\title{
Applying $\mathrm{Ag}-\mathrm{TiO}_{2} /$ functional filter for abating odor exhausted from semiconductor and opti-electronic industries
}

\author{
Yu-Chih Lin
}

Received: 28 February 2012/ Accepted: 9 August 2012/Published online: 24 August 2012

(C) The Author(s) 2012. This article is published with open access at Springerlink.com

\begin{abstract}
Some of the odor-related problems from the semiconductor and opti-electronic industries are caused by the volatile organic compounds, acetic acid, and dimethyl sulfide. These odorous exhausts would persecute residents' health and lower the environmental quality. In this study, $\mathrm{Ag}-\mathrm{TiO}_{2} /$ functional filter was applied to removal these odorous compounds. The results indicated that $\mathrm{K}_{2} \mathrm{CO}_{3}$ / activated carbon filter (ACF) would be the better composition of functional filter, which attributed to larger surface area of ACF and mid-alkalinity of $\mathrm{K}_{2} \mathrm{CO}_{3}$. Comparing the $\mathrm{TiO}_{2}$ type, $\mathrm{P} 25 \mathrm{TiO}_{2}$ (Degussa, Germany)/functional filter showed the more superior photodegradation efficiency than ST01 $\mathrm{TiO}_{2}$ (Ishihra Sangyo, Japan)/functional filter. In addition, Ag-modifying $\mathrm{TiO}_{2} /$ functional filter enhanced the photocatalysis via postponing the recombination between electrons and holes. The $0.001 \mathrm{M} \mathrm{AgNO}_{3}$ solution was the optimal immersing concentration to make $\mathrm{Ag}$ dispersed uniformly on $\mathrm{TiO}_{2}$ surface. Operating from 25 to $50{ }^{\circ} \mathrm{C}$, the rising temperature was contributive to photodegradation efficiency due to the increase of system reaction energy. Processing photocatalysis below $75 \%$ of relative humidity, existing humidity could be combined with holes to from hydronium $\left(\mathrm{H}_{3} \mathrm{O}^{+}\right)$and hydroxyl radical $\left(\mathrm{OH}^{-}\right)$to improve photodegradation. Assisted with ozone concentration ratio of 0.7 times, the removal efficiency for high pollutant concentration via $\mathrm{Ag}-\mathrm{TiO}_{2} /$ functional filter could be improved up to $90 \%$ until operating $180 \mathrm{~min}$; this combined method could save the oxidant consumption more than single advanced oxidation method for processing pollutant.
\end{abstract}

Y.-C. Lin $(\bowtie)$

Department of Environmental Engineering and Health, Yuanpei

University, 306 Yuan-Pei Street, Hsin-Chu City 300, Taiwan

e-mail: yuchihlin@mail.ypu.edu.tw
Keywords Photocatalysis - Adsorption - Deodorization · Volatile organic compounds - Activated carbon filter

\section{Introduction}

A greater part of semiconductor and opti-electronic industries in Taiwan are located at Hsinchu Science-Based Industrial Park (SBIP), which is the so-called "Taiwan Silicon Valley." Abating the air pollution from SBIP, Taiwan environmental protection agency revised the "The Standard of Air Pollutant Emission from the Stationary Source," and promoted "The Standard of Odorous Emission" stricter in September, 2007. Owing to stringent environmental regulations in Taiwan as well as increasing concerns from neighboring residents, the request of air quality becomes more and more, especially the deodorization in the atmosphere. Some of the odorous problems from the semiconductor and opti-electronic industries are caused by the volatile organic compounds (VOCs), acetic acid, and dimethyl sulfide (DMS). VOCs and acetic acid are necessary materials in the manufacturing processes. DMS was transferred from the dimethyl sulfoxide (DMSO), which is one of main compounds in the stripper. These odorous exhausts would persecute residents' health and lower the environmental quality in the neighborhood of SBIP. The deodorization methods include adsorption (Le Leuch et al. 2003, 2005), absorption (Couvert et al. 2006), catalytic oxidation (Pope et al. 1977; Rossin 1989; Ok et al. 1993), plasma destruction (Okubo et al. 2007), and advanced oxidation (Lesauze et al. 1991), etc. These processes will be operated on the high efficiency. But, the traditional adsorbent will be replaced frequently on the operation; the high voltage in plasmas' destruction and high temperature in catalytic oxidation will cause the 
potential risk for the staffs. In addition, the large oxidant tank is necessary in advanced oxidation, but the tank occupied the factory space and the oxidant leak will be taken precautions. Titanium dioxide $\left(\mathrm{TiO}_{2}\right)$ has been widely applied and proven efficiently on decontamination, sterilization, and deodorization, as well as removing VOCs (Zuo et al. 2006; Kim et al. 2006; Yu et al. 2007). Recently, the photodecomposition efficiency of pollutant on $\mathrm{TiO}_{2}$ can be enhanced by modifying the surface with sliver (Ag) (Einaga 2006; Young et al. 2008; Shie et al. 2008; Lee et al. 2009). Sclafani and Herrmann (1998) indicated that in addition to postponing the recombination between electrons and holes. Another advantage of utilizing Ag-modified $\mathrm{TiO}_{2}$ for enhancing photocatalysis is due to it being more economical than the other noble metals (Vamathevan et al. 2002). $\mathrm{TiO}_{2}$-combined porous adsorbent could also enhance the removal efficiency of target pollution due to the dual mechanisms of photocatalysis and adsorption. In addition, the adsorbent would concentrate the pollutant on the $\mathrm{TiO}_{2}$ surface and improve the interaction between the pollutant and $\mathrm{TiO}_{2}$ in the photocatalysis process, thus better the removal efficiency (Jan et al. 2009; Chang and Lin 2009; Ye et al. 2009; Jo and Yang 2009). The removal mechanism of pollutant by $\mathrm{TiO}_{2}$ combined with adsorbent, such as activated carbon, would be contributed to the adsorption and photocatalysis method. Physical adsorption and chemical adsorption are the mechanisms of VOCs' removal by adsorption method. Physical adsorption is contributed to Van der Waal's forces, which are intermolecular attractive forces between the adsorbate and the adsorbent. In addition, the Van der Waal's force is consisted of London-dispersion force and classical electrostatic interaction force. Chemisorption is caused from the attraction of chemical bonds between the chemical functional group on the surface of adsorbent and adsorbate (Oura et al. 2003). Under ultra violet (UV) illumination, $\mathrm{TiO}_{2}$ excites electron-hole pairs that can disrupt the molecular structure of target pollutants, breaking the bonds, and resulting in inorganic material. In addition, the active free radical, such as hydroxy radical $\left(\mathrm{OH}^{-}\right)$, superoxide radical $\left(\mathrm{O}_{2}{ }^{-}\right)$, perhydroxy radical $\left(\mathrm{HO}_{2} \cdot\right)$, which are the product from the interaction of electron-hole, would be also oxidized with pollutant (Hoffmann et al. 1995).

In this study, the functional filter was loaded with $\mathrm{TiO}_{2}$ modified by $\mathrm{Ag}$ for synthesizing $\mathrm{Ag}-\mathrm{TiO}_{2} /$ functional filter, and utilized for photodegrading these odorous compounds to improve the above-mentioned problems. The carriers of functional filters were chosen as activated carbon fiber (ACF), aluminum oxide, and Y-type zeolite. Potassium oxalate $\left(\mathrm{K}_{2} \mathrm{C}_{2} \mathrm{O}_{4}-\mathrm{H}_{2} \mathrm{O}\right)$, potassium permanganate $\left(\mathrm{K}_{2} \mathrm{MnO}_{4}\right)$, potassium carbonate $\left(\mathrm{K}_{2} \mathrm{CO}_{3}\right)$, and potassium hydroxide $(\mathrm{KOH})$ were arranged as alkali agent, coated on the tested carrier. The results are expected to study the appropriate carrier; chemical composition combined with Ag-modified $\mathrm{TiO}_{2}$ to removal the odor well. The $\mathrm{TiO}_{2}$ type, Ag dosage modified on $\mathrm{TiO}_{2}$, and the operational parameters are the effect factors on the photodegradation efficiency to discuss. It is expected that the functional filter deals odor with the adsorption and absorption without UV irradiation; $\mathrm{Ag}-\mathrm{TiO}_{2}$ also exert the photocatalytic decontamination with UV irradiation. This method would be expected to improve the service life of the adsorption medium, and enhance the photocatalysis performance. Furthermore, the results are also foundations to develop deodorization devices in the industries, office, and house.

\section{Experiments}

Synthesis of functional filter

ACF (AW1101 KoTHmex, Taiwan Carbon Company), Y-type zeolite (CBV 780, Zeolyst), and aluminum oxide (AC108, NanoScale Corporation) were utilized as the carriers, and the adsorption capacity of carrier for acetic acid was determined via adsorption breakthrough of acetic acid. The best one was weighed as $10.0 \mathrm{~g}$ and immersed in the $100 \mathrm{ml}$ solution of $0.1 \mathrm{M}$ potassium composition for $8 \mathrm{~h}$ and drying the catalyst at $100{ }^{\circ} \mathrm{C}$ for the other $8 \mathrm{~h}$ and then functional filter was gained after the temperature decreasing to normal condition. The potassium compositions were chosen as $\mathrm{K}_{2} \mathrm{C}_{2} \mathrm{O}_{4}-\mathrm{H}_{2} \mathrm{O}, \mathrm{K}_{2} \mathrm{MnO}_{4}, \mathrm{~K}_{2} \mathrm{CO}_{3}$, and $\mathrm{KOH}$; each immersion solution was composed of individual potassium composition.

\section{Synthesis of $\mathrm{Ag}-\mathrm{TiO}_{2} /$ functional filter}

The synthesis procedure of $\mathrm{Ag}-\mathrm{TiO}_{2}$ was as follows: $5 \mathrm{~g}$ of $\mathrm{TiO}_{2}$ particles was suspended and stirred in an $\mathrm{AgNO}_{3}$ aqueous solution $(167 \mathrm{ml})$ at different concentrations $\left(10^{-3}, 10^{-2}\right.$, and $\left.10^{-1} \mathrm{M}\right)$. The mixture was then exposed to 365-nm UVA light $(6 \mathrm{~W})$ for $10 \mathrm{~min}$. After the irradiation, the precipitate was filtered with deionized water to remove any residues and dried in the oven for $2 \mathrm{~h}$. Ag$\mathrm{TiO}_{2} /$ functional filter was prepared with a dip-coating method for the subsequent photocatalysis test.

Examining system of target pollutant removal efficiency

Figure 1 illustrated the experimental apparatus composed of some units, including the gaseous generation units, a photocatalysis reactor with a quartz glass window $(2.0 \mathrm{~cm}$ of inner diameter), and the gas analysis units. A dry-grade compressed gas tank was used to carrier stream. The concentration of acetic acid and isopropyl alcohol (IPA) in the flow was obtained by passing the air through a midget impinger. DMS is 
Fig. 1 Examining system of target pollutant removal efficiency. 1 Air cylinder and valve, 2 humidity and HEPA filter, 3 mass flow control, 4 acetic acid/IPA impinger in thermostatic water bath, 5 DMS cylinder, 6 ozone generator, 7 mixing chamber, 8 photocatalysis/adsorption system in thermostat, 9 ozone analyzer, 10 acetic acid analyzer, $11 \mathrm{GC} / \mathrm{FID}, 12$ total sulfur analyzer

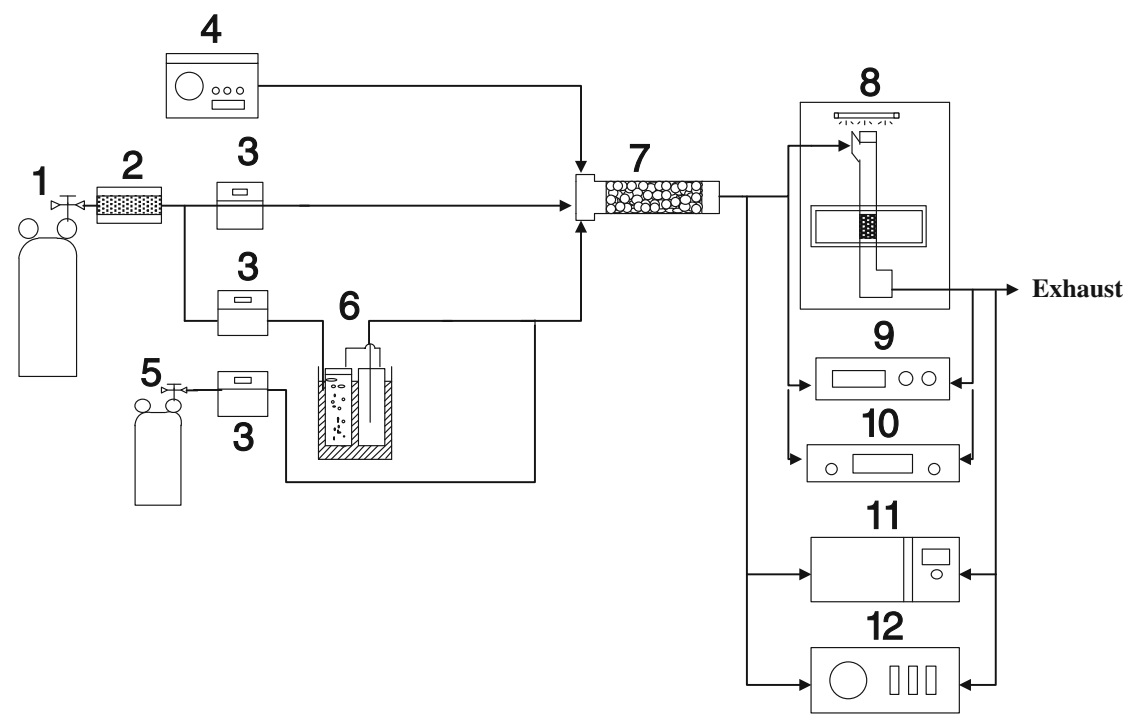

supplied from the high-pressure cylinder, the ozone generator (TR300, Tairex) was used to produce ozone, and ozone was analyzed by ozone analyzer (Model 49i, Thermo Scientific). The acetic acid, IPA, DMS, and the dilution flow were controlled by mass flow controllers (5850E, BROOK USA), respectively. The total flow rate, acetic acid, IPA, and DMS concentration flowing into the reactor were $2 \mathrm{lpm}(0.11 \mathrm{~m} / \mathrm{s}$ of linear velocity), and $50 \mathrm{ppmv}$, respectively. The pollutant concentrations used in this study were decided according the design size of reactor, coating dosage of photocatalyst, and detection range of instrument. All experiments were performed using a photocatalysis reactor, which was placed in the thermostat, and the packed weight of $\mathrm{Ag}-\mathrm{TiO}_{2} /$ functional filter was $0.03 \mathrm{~g}$ including $0.005 \mathrm{~g}$ photocatalyst. A $10-\mathrm{W}$ UVA light was set on top of reactor with a quartz glass window, about $20 \mathrm{~cm}$ from the packed photocatalyst; the luminance of light source over the filter was $0.7 \mu \mathrm{W} / \mathrm{cm}^{2}$. The acetic acid concentrations at the inlet and the outlet of the reactors were analyzed using acid-gas analyzer (B12 2-wire gas transmitter, ATI USA); the IPA concentrations of process flow before and after the system were measured by gas chromatography using flame ionization detector (GC/FID, YL6100, Young Lin Instrument, Korea) with Quadrex 007-5 column. The DMS concentrations at the inlet and the outlet of the testing reactors were analyzed by total sulfur oxides analyzer (Model 43i, Thermo Scientific). The photodegradation efficiency of acetic acid, IPA, and DMS were determined from the percentage difference between inlet and outlet concentration divided by inlet concentration.

\section{Results and discussions}

Figure 2 illustrates the comparisons of removal efficiency between ACF, Y-type zeolite, and aluminum oxide on processing acetic acid. The efficiency of the ACF was significantly greater than that of the other; the efficiencies of the Y-type zeolite and the aluminum oxide were similar in this experiment.

The results could be attributed to the surface area of tested carrier. Table 1 indicates the BET surface area of tested carrier measured by a surface area analyzer (Micromeritics model ASAP2020, USA). The surface area of ACF, Y-type zeolite, and aluminum oxide were 1,100, 780, and $550 \mathrm{~m}^{2} / \mathrm{g}$, respectively; the increasing surface area of tested carriers were in proportion to the removal efficiency. The function group on the surface of tested carriers is also the influence factor and would be discussed in the further study.

The effects of different potassium composition modifying ACF on the removal efficiency were illustrated on the Fig. 3. The results show the obverse correlations between removal efficiency and the alkalinity of potassium composition. The $\mathrm{pH}$ values in the $0.1 \mathrm{M}$ solution of each potassium composition were measured using $\mathrm{pH}$ meter (Model60, Jenco, Taiwan); the $\mathrm{pH}$ of $\mathrm{K}_{2} \mathrm{C}_{2} \mathrm{O}_{4}-\mathrm{H}_{2} \mathrm{O}$, $\mathrm{K}_{2} \mathrm{MnO}_{4}, \mathrm{~K}_{2} \mathrm{CO}_{3}$, and $\mathrm{KOH}$ solutions were $7.26,7.47$, 10.65 and 12.49 , respectively. The enhanced removal efficiency of acetic acid was related to the increasing alkalinity. As shown, the difference of removal efficiency between the $\mathrm{K}_{2} \mathrm{CO}_{3} / \mathrm{ACF}$ and the $\mathrm{KOH} / \mathrm{ACF}$ was not very conspicuous. Therefore, $\mathrm{K}_{2} \mathrm{CO}_{3} / \mathrm{ACF}$ was suggested to be the composition of functional filter for removal acid odor, based on the good performance and harmless mid-alkalinity of coating agent.

Figure 4 indicated that ACF processed the IPA and acetic acid well on the adsorption, but not outstanding for DMS. The adsorption efficiency of acetic acid, IPA, and DMS on ACF were in proportion to the boiling point. The boiling points of acetic acid, IPA, and DMS were 118.1, 


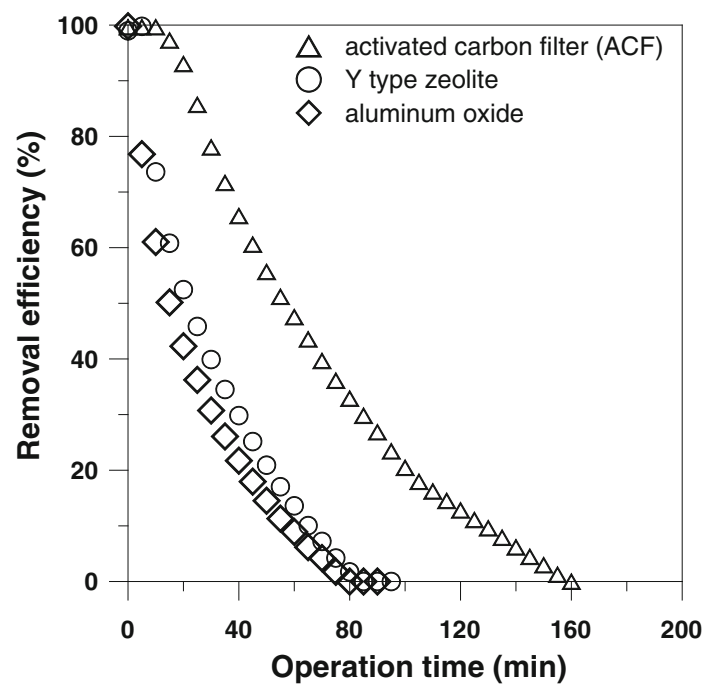

Fig. 2 Removal efficiency of acetic acid on tested carriers

Table 1 Surface area of tested carriers

\begin{tabular}{llll}
\hline Tested carrier & ACF & Y-type zeolite & Aluminum oxide \\
\hline BET surface area $\left(\mathrm{m}^{2} / \mathrm{g}\right)$ & 1,100 & 780 & 550 \\
\hline
\end{tabular}

82.5 and $37{ }^{\circ} \mathrm{C}$, respectively. The alkalinity on the functional filter, which was synthesized by ACF immersed in $\mathrm{K}_{2} \mathrm{CO}_{3}$ solution, enhanced the removal efficiency of acetic acid and DMS. The potassium compositions might also react with DMS and improved the odorous exhaust. In addition, functional filter processed the IPA on the same performance with ACF; this result indicated that the original adsorption sites on functional filter were not destroyed, and the functional filter has the adsorption property for the multi-pollutant.

$\mathrm{TiO}_{2} /$ functional filter under UVA irradiation increased the removal efficiencies of three targets pollutants; its performance was better than that of single adsorption mechanism. Besides concentrating pollution on the $\mathrm{TiO}_{2}$ surface, ACF playing as the adsorbent would enhance interaction between $\mathrm{TiO}_{2}$ and pollution and then increases the removal efficiency. Comparing $\mathrm{P} 25 \mathrm{TiO}_{2}$ (Degussa, Germany)/functional filter with ST01 $\mathrm{TiO}_{2}$ (Ishihra Sangyo, Japan)/functional filter, the photodegradation performance of target pollutants on $\mathrm{P} 25 \mathrm{TiO}_{2} /$ functional filter was superior. The reason was $\mathrm{P} 25 \mathrm{TiO}_{2}$ characterized as the better adsorption and enhanced quantum effect, which were contributed to greater surface area, $300 \mathrm{~m}^{2} / \mathrm{g}$, and smaller particle size, $7 \mathrm{~nm}$. This situation was agreed with the result of Grabowska et al. (2010). Thus, $\mathrm{P} 25 \mathrm{TiO}_{2}$ was chosen for the subsequent photocatalyst materials. The photodecomposition efficiency of pollutant on $\mathrm{P} 25 \mathrm{TiO}_{2}-$ modified $\mathrm{Ag}$ combined with functional filter $\left(\mathrm{Ag}-\mathrm{TiO}_{2} /\right.$

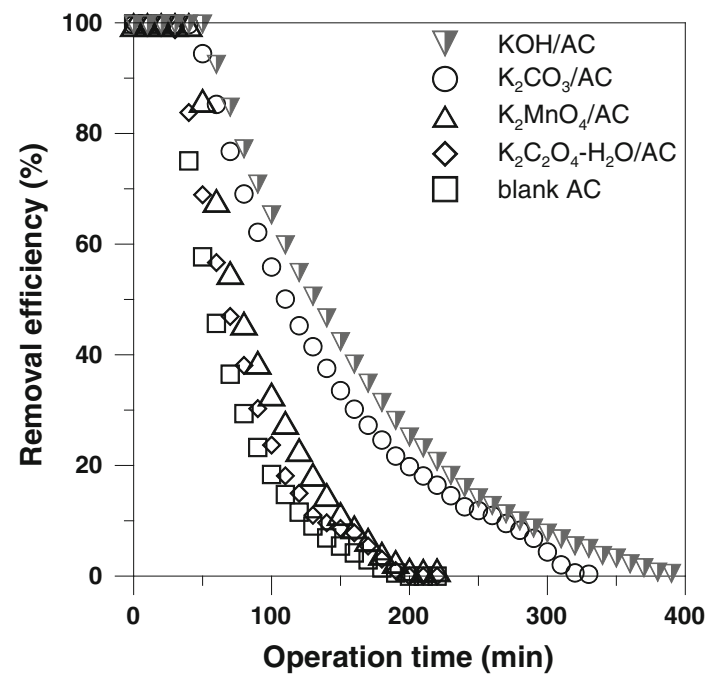

Fig. 3 Removal efficiency of acetic acid on the ACF coated different potassium compositions

functional filter) was better than that of the other materials. Postponing the recombination between electrons and holes is the role that $\mathrm{Ag}$ enhances the photocatalysis. $\mathrm{Ag}-\mathrm{TiO}_{2} /$ functional filter under UVA irradiation combines both photocatalysis and adsorption. The removal reaction rates of ST01 $\mathrm{TiO}_{2} /$ functional filter, $\mathrm{P} 25 \mathrm{TiO}_{2} /$ functional filter, and $\mathrm{Ag}-\mathrm{P} 25 \mathrm{TiO}_{2}$ /functional filter for target pollutant were listed on Table 2. The target pollutants in photocatalysis process would be degraded to $\mathrm{CO}, \mathrm{CO}_{2}$, and the other intermediate. During photocatalysis process, the byproduct of IPA was acetone and then degrade to $\mathrm{H}_{2} \mathrm{O}$ and $\mathrm{CO}_{2}$ (Larson et al. 1995); the acetic acid decomposed to $\mathrm{CH}_{4}$, $\mathrm{CO}_{2}$, and $\mathrm{C}_{2} \mathrm{H}_{6}$ (Muggli, and Falconer, 1999); DMS would degrade to dimethyl sulfoxide (DMSO), dimethyl sulfone $\left(\mathrm{DMSO}_{2}\right)$, dimethyl disulfide (DMDS), methanethiol (MT), methanesulfonic acid (MSA), and sulfate (Wang et al. 2011). This situation helped to postpone the adsorption breakthrough, maintained the specific photocatalysis performance above $30 \%$, and avoided the adsorption saturated. The mass balance and mineralization efficiency of IPA, acetic acid, and DMS on $\mathrm{Ag}-\mathrm{TiO}_{2} /$ functional filter would be discussed in the future study. Effects of the operational parameters on the photodegradation efficiency would be discussed at each operated time of $180 \mathrm{~min}$ for the subsequent experiments; the adsorption could be eliminated from the photodegradation efficiency.

Figure 5 showed the photodegradation efficiency of target pollutants increased with decreasing $\mathrm{AgNO}_{3}$ immersing solution concentration for synthesizing $\mathrm{Ag}-$ $\mathrm{TiO}_{2} /$ functional filter. The appropriate precursor concentration made $\mathrm{Ag}$ in nanoscale dispersed uniformly on $\mathrm{TiO}_{2}$ surface, which was beneficial for avoiding the Ag particles accumulated, not blocking the surface area of $\mathrm{TiO}_{2}$ from 

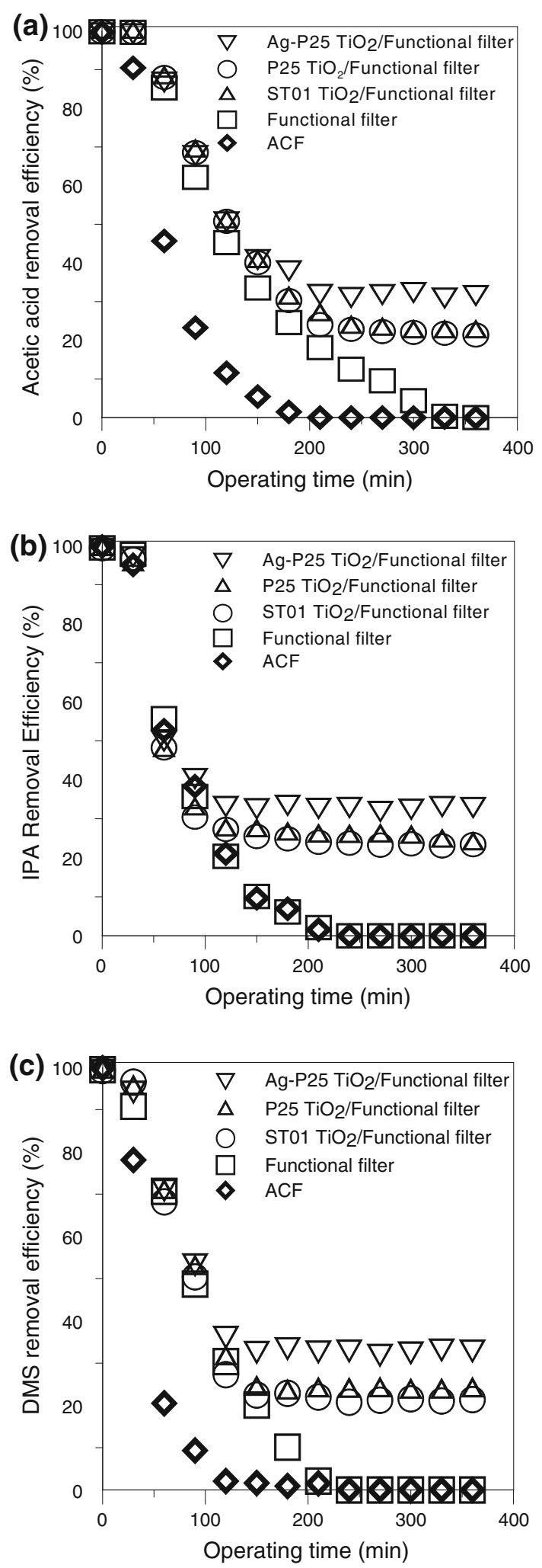

Fig. 4 Removal efficiency of target pollutant between ACF, functional filter, $\mathrm{TiO}_{2}$ /functional filter under UVA irradiation, and $\mathrm{Ag}-$ $\mathrm{TiO}_{2}$ /functional filter under UVA irradiation: a acetic acid, b IPA, c DMS
Table 2 Removal reaction rate of $\mathrm{ST} 01 \mathrm{TiO}_{2} /$ functional filter, P25 $\mathrm{TiO}_{2} /$ functional filter, and $\mathrm{Ag}-\mathrm{P} 25 \mathrm{TiO}_{2} /$ functional filter for target pollutant

\begin{tabular}{llll}
\hline $\begin{array}{l}\text { Target } \\
\text { pollutant }\end{array}$ & \multicolumn{2}{l}{ Removal reaction rate by catalyst $\left(\mathrm{min}^{-}\right)$} \\
\cline { 2 - 4 } & $\begin{array}{l}\mathrm{ST01} \\
\mathrm{TiO}_{2} / \text { functional } \\
\text { filter }\end{array}$ & $\begin{array}{l}\mathrm{P} 25 \\
\mathrm{TiO}_{2} / \text { functional } \\
\text { filter }\end{array}$ & $\begin{array}{l}\mathrm{Ag}-\mathrm{P} 25 \\
\mathrm{TiO}_{2} / \text { functional } \\
\text { filter }\end{array}$ \\
\hline Acetic acid & 0.1672 & 0.1693 & 0.191 \\
IPA & 0.1739 & 0.1794 & 0.193 \\
DMS & 0.1701 & 0.1757 & 0.2022 \\
\hline
\end{tabular}

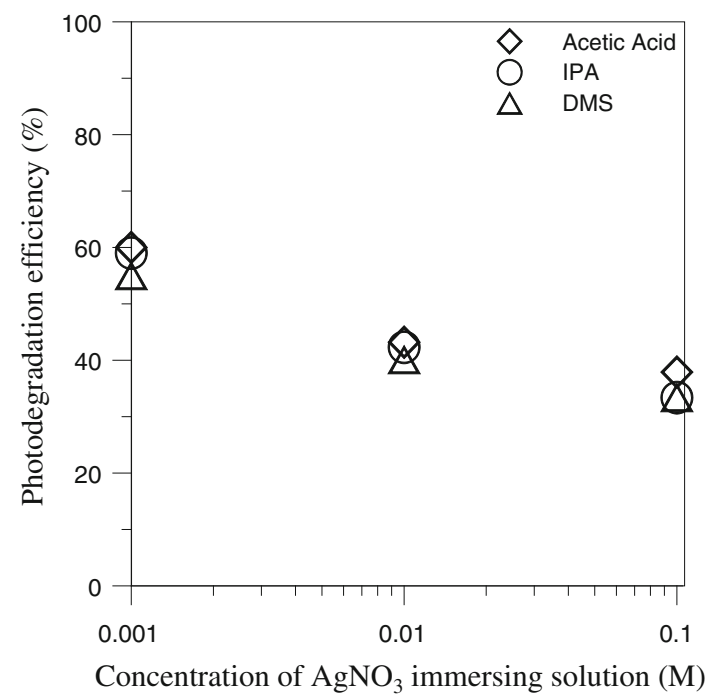

Fig. 5 Effect of $\mathrm{AgNO}_{3}$ immersing solution concentration on the removal efficiency of target pollutants via $\mathrm{Ag}-\mathrm{TiO}_{2} /$ functional filter under UVA irradiation

UVA irradiation, and extending the interactive area between pollutants and photocatalyst (Lin and Lin 2008). In addition, the smaller nano-Ag particles had better quantum size effects to enhance catalysis. It is deserve to be mentioned, the very fewer $\mathrm{AgNO}_{3}$ solution concentration, which is not shown in Fig. 4, would cause the Ag on $\mathrm{TiO}_{2}$ surface too insufficient to improve the photocatalysis.

Figure 6 indicated that the increasing temperature from 25 to $50{ }^{\circ} \mathrm{C}$ was contributive to the removal efficiency acetic acid and IPA, but unfavorable for DMS due to the low boiling point of $37^{\circ} \mathrm{C}$. Besides accelerating chemical reaction between the acetic acid and $\mathrm{K}_{2} \mathrm{CO}_{3}$ coated on functional filter consequentially, temperature increase implies an increase of system reaction energy, facilitating a rise of photodegradation efficiency. However, temperature raising up to $75^{\circ} \mathrm{C}$ facilitated photodegradation efficiency decreasing. The reason is that higher temperature accelerates the recombination rate of electron-hole pairs excited 


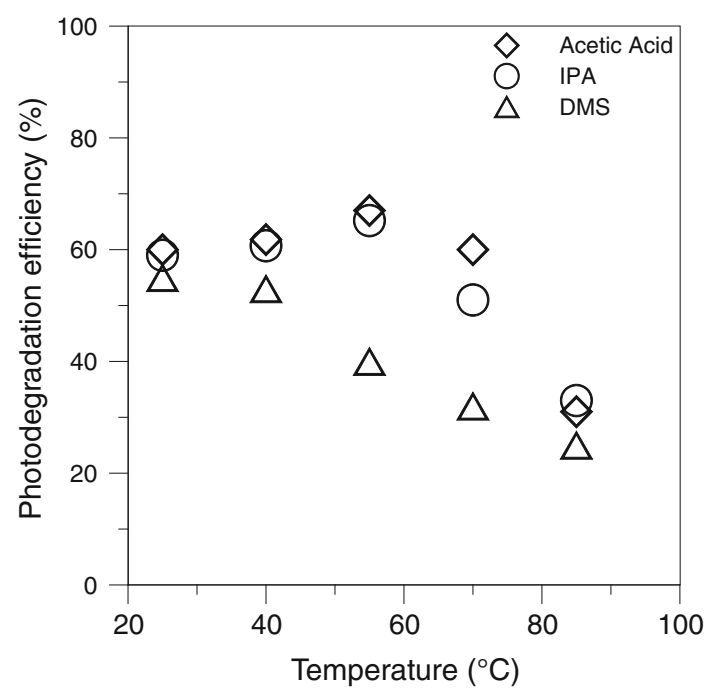

Fig. 6 Effect of operating temperature on the removal efficiency of target pollutants via $\mathrm{Ag}-\mathrm{TiO}_{2} /$ functional filter under UVA irradiation

from irradiated $\mathrm{TiO}_{2}$ and lowers photocatalysis efficiency, which is consistent with the literature (Rauf and Ashraf 2009). In addition, the adsorbed pollutants would be desorbed from the adsorbent at the higher temperature, hence the removal efficiency turned down.

The influence of humidity on the target removal efficiency via $\mathrm{Ag}-\mathrm{TiO}_{2} /$ functional filter under UVA irradiation was also examined under UVA irradiation, as illustrated in Fig. 7. At a relative humidity (RH) of $75 \%$, the target removal efficiency was less than those at lower RH. The hydrophilic characteristic of $\mathrm{ACF}$ and $\mathrm{TiO}_{2}$ favor moisture adsorption and then the moisture occupies the adsorption sites on their surface, reducing the adsorption performance; furthermore, more moisture also accelerates the recombination of the electron-

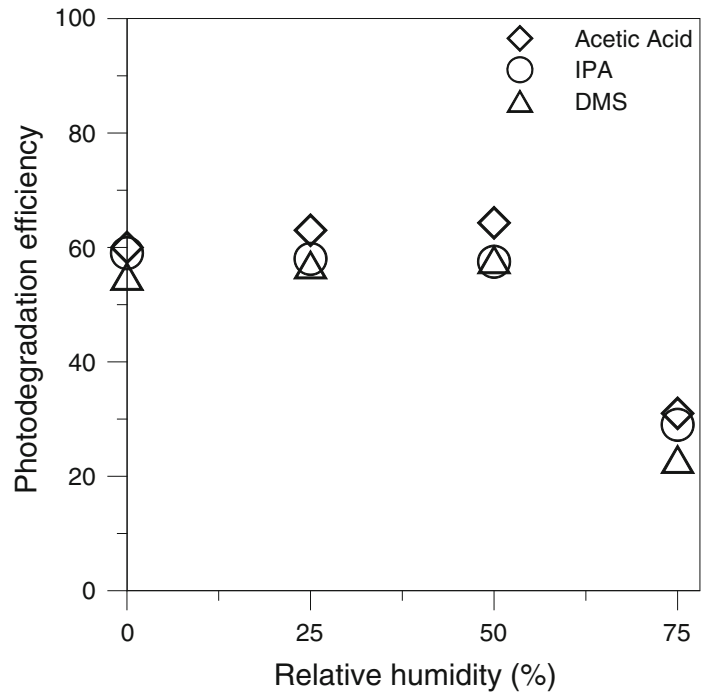

Fig. 7 Effect of operating humidity on the removal efficiency of target pollutants via $\mathrm{Ag}-\mathrm{TiO}_{2} /$ functional filter under UVA irradiation hole pair during photocatalysis process (Anpo et al. 1991). The above-mentioned occasions lead the target removal efficiency to degeneracy above RH of $75 \%$. The target removal efficiencies between RH of 0 and $50 \%$ remained the good performance and the difference was very slight. In the photocatalysis process, the $\mathrm{H}_{2} \mathrm{O}$ would be combined with holes to from hydronium $\left(\mathrm{H}_{3} \mathrm{O}^{+}\right)$and hydroxyl radical $\left(\mathrm{OH}^{-}\right)$, as the humidity in the environment is not much. These behaviors would be contributive to postpone the recombination between electrons and holes, the $\mathrm{H}_{3} \mathrm{O}^{+}$and $\mathrm{OH}^{-}$would be reacted with target pollutants to improve photocatalysis in the meantime. Hence, the photogradation efficiency and competitive adsorption of moisture would be on the pseudo-equilibrium.

Figure 8 indicated that effect of ozone assistance on the target removal efficiency via $\mathrm{Ag}-\mathrm{TiO}_{2} /$ functional filter under UVA irradiation. Ozone inlet concentration as the 0.1 times of target pollutants concentration is defined as ozone concentration ratio of 0.1 times $\left(0.1 \times \mathrm{O}_{3}\right.$ con. ratio). The assistant ozone enhanced removal efficiency substantially in comparison with the single photocatalysis process, on the ozone concentration ratio between 0.1 and 0.7. The removal efficiency via $\mathrm{Ag}-\mathrm{TiO}_{2} /$ functional filter under UVA irradiation assisted with $0.7 \times$ ozone con. ratio of could be enhanced up to $90 \%$. Comparing with the results of Chang et al. (2008), which indicated that the copper catalyst and $\mathrm{K}_{2} \mathrm{CO}_{3} / \mathrm{ACF}$ assisted with $1.5 \times$ ozone con. ratio could process DMS and acetic acid on the same performance. Thus, photocatalytic ozonation method could save the oxidant consumption in a more than advanced oxidation method for processing pollutant. However, on increasing the ozone concentration ratio to $0.9 \times$, the removal efficiency declined conspicuously. This decay could be as a result of the competitive phenomenon

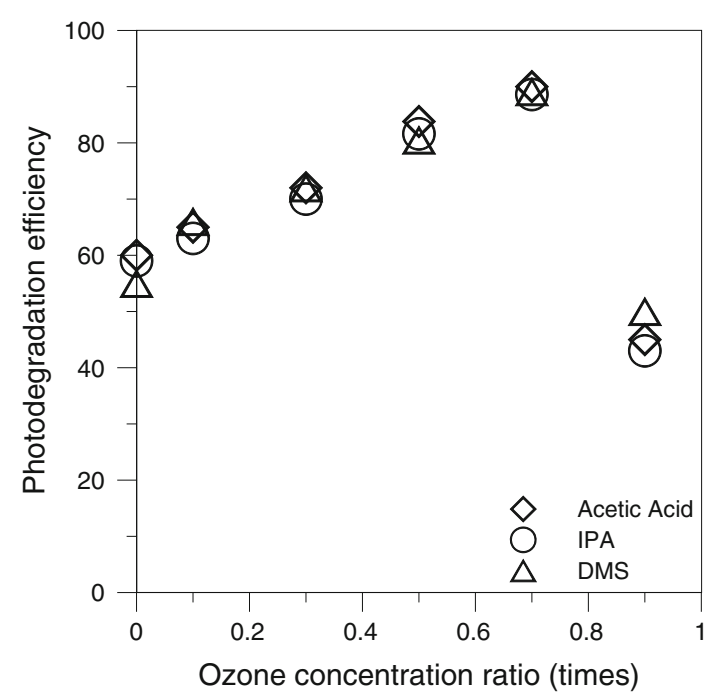

Fig. 8 Effect of ozone assistance on the removal efficiency of target pollutants via $\mathrm{Ag}-\mathrm{TiO}_{2} /$ functional filter under UVA irradiation 
between ozone and target pollutants on $\mathrm{Ag}-\mathrm{TiO}_{2} /$ functional filter or the excess of ozone deactivated or destroyed the functional group on the surface of $\mathrm{Ag}-\mathrm{TiO}_{2} /$ functional filter.

\section{Conclusion}

Because of the larger surface area and some functional group on surface, ACF possesses the best removal efficiency among the tested carriers. The $\mathrm{K}_{2} \mathrm{CO}_{3} / \mathrm{ACF}$ was suggested to be the composition of functional filter for removal atmospheric acid odor due to good performance and harmless mid-alkalinity of coating agent. Characterizing as the better adsorption and enhanced quantum effect, P25 $\mathrm{TiO}_{2}$ /functional filter was more superior that ST01 $\mathrm{TiO}_{2} /$ function filter on photodegrading acetic acid. In addition, Ag modifying $\mathrm{TiO}_{2}$ surface postponed the recombination between electrons and holes and enhanced the photocatalysis. $\mathrm{Ag}-\mathrm{TiO}_{2} /$ functional filter under UVA irradiation combines both photocatalysis and adsorption; the appropriate $\mathrm{AgNO}_{3}$ immersing solution concentration made $\mathrm{Ag}$ dispersed uniformly on $\mathrm{TiO}_{2}$ surface, avoiding the Ag particles accumulated, and not to block the surface area of $\mathrm{TiO}_{2}$ under the UVA irradiation.

Operating temperature rising from 25 to $50{ }^{\circ} \mathrm{C}$ was contributive to photodegradation efficiency due to the increase of system reaction energy. However, temperature higher than $75{ }^{\circ} \mathrm{C}$ accelerated the recombination of electron-hole pairs excited from irradiated $\mathrm{TiO}_{2}$ and facilitated the pollutant to be desorbed from functional filter resulting in removal efficiency decline. In photocatalysis process, $\mathrm{H}_{2} \mathrm{O}$ could be combined with holes to from hydronium $\left(\mathrm{H}_{3} \mathrm{O}^{+}\right)$and hydroxyl radical $\left(\mathrm{OH}^{-}\right)$to improve photodegradation; however, more moisture not only occupied the adsorption sites but also accelerated the recombination of the electron-hole pair, then decreased the pollutant removal efficiency. Assisted with ozone concentration ratio of 0.7 times, the removal efficiency via $\mathrm{Ag}-\mathrm{TiO}_{2} /$ functional filter under UVA irradiation could be enhanced up to $90 \%$; this combined method could save the oxidant consumption more than single advanced oxidation method for processing pollutant. However, the ozone concentration ratio increasing to 0.9 , the competitive phenomenon between ozone and target pollutants happened on $\mathrm{Ag}-$ $\mathrm{TiO}_{2} /$ functional filter, and the excess ozone deactivated the function group on the surface of $\mathrm{Ag}-\mathrm{TiO}_{2} /$ functional filter resulting in removal efficiency decay.

Owing to adsorption, absorption, and photocatalysis characteristics, the $\mathrm{Ag}-\mathrm{TiO}_{2} /$ functional filter developed in this study could show the better performance on the multipollutant removal, no matter under or without UV irradiation. In addition, the $\mathrm{Ag}-\mathrm{TiO}_{2} /$ functional filter act as a potential for finding an effective device of indoor air clean with/without UV illumination.

Acknowledgments The author deeply appreciated the National Science Council, Taiwan for the financial support (NSC 99-2221-E264-004-MY3; NSC96-2628-E-264-001-MY3) in this study.

Open Access This article is distributed under the terms of the Creative Commons Attribution License which permits any use, distribution, and reproduction in any medium, provided the original author(s) and the source are credited.

\section{References}

Anpo M, Chiba K, Tomonari M, Coluccia S, Che M, Fox MA (1991) Photocatalysis on native and platinum-load $\mathrm{TiO}_{2}$ and $\mathrm{ZnO}$ catalysts. Bull Chem Soc Jpn 64:543-551

Chang CP, Lin Y (2009) Enhancement effect of double-layer $\mathrm{TiO}_{2} /$ activated carbon film for the photocatalytic oxidation of gaseous acetone. Fresenius Environ Bull 18:968-974

Chang CN, Lin Y, Chang FT, Huang CL (2008), Room temperature catalyst assisted with ozone for deodorizing the gas contamination of dimethyl sulfide. 26th Annual technical meeting on air cleaning and contamination control, Tokyo, Japan

Couvert A, Charron I, Laplanchea A, Rennerb C, Patriab L, Requiemec B (2006) Treatment of odorous sulphur compounds by chemical scrubbing with hydrogen peroxide: application to a laboratory plant. Chem Eng Sci 61:7240-7248

Einaga $\mathrm{H}$ (2006) Effect of silver deposition on $\mathrm{TiO}_{2}$ for photocatalytic oxidation of benzene in the gas phase. React Kinet Catal Lett 88:357-362

Grabowska E, Remita H, Zaleska A (2010) Photocatalytic activity of $\mathrm{TiO}_{2}$ loaded with metal clusters. Physicochem Probl Miner Process 45:29-38

Hoffmann MR, Martin ST, Choi WY, Bahnemann DW (1995) Environmental applications of semiconductor photocatalysis. Chem Rev 95:69-96

Jan YH, Lin LY, Karthik M, Bai HL (2009) Titanium dioxide/zeolite catalytic adsorbent for the removal of no and acetone vapors. J Air Waste Manag Assoc 59:1186-1193

Jo WK, Yang CH (2009) Granular-activated carbon adsorption followed by annular-type photocatalytic system for control of indoor aromatic compounds. Sep Purif Technol 66:438-442

Kim FH, Ogata A, Futamura S (2006) Effect of different catalysts on the decomposition of VOCs using flow-type plasma-driven catalysis. IEEE Trans Plasma Sci 34:984-995

Larson SA, Widegren JA, Falconer JL (1995) Transient studies of 2-propanol photocatalytic oxidation on titania. J Catal 157:611-625

Le Leuch LM, Subrenat A, Le Cloirec P (2003) Hydrogen sulfide adsorption and oxidation onto activated carbon cloths: applications to odorous gaseous emission treatments. Langmuir 19:10869-10877

Le Leuch LM, Subrenat A, Le Cloirec P (2005) Hydrogen sulfide and ammonia removal on activated carbon fiber cloth-supported metal oxides. Environ Technol 26:1243-1254

Lee SL, Scott J, Chiang K, Amal R (2009) Nanosized metal deposits on titanium dioxide for augmenting gas-phase toluene photooxidation. J Nanopart Res 11:209-219

Lesauze N, Laplanche A, Martin G, Paillard H (1991) A process of washing and ozonation to deodorize an atmosphere contaminated by sulfides. Ozone Sci Eng 13:331-347 
Lin Y, Lin C (2008) Degradation of ozone via utilization of controllable nano-Ag modified on $\mathrm{TiO}_{2}$. Environ Prog 27:96-502

Muggli DS, Falconer JL (1999) Parallel pathways for photocatalytic decomposition of acetic acid on $\mathrm{TiO}_{2}$. J Catal 187:230-237

Ok G, Hanai Y, Katou T (1993) Decomposition of chlorinated dioxins, odorous compounds and NOx from MSW incineration plant by oxidizing catalyst. Chemosphere 26:2167-2172

Okubo M, Kametaka H, Yoshida K, Yamamoto T (2007) Odor removal characteristics of barrier-type packed-bed nonthermal plasma reactor. Jpn J Appl Phys 1(46):5288-5293

Oura K, Lifshits VG, Saranin AA, Zotov AV, Katayama M (2003) Surface science: an introduction. Springer, Berlin. ISBN 3-54000545-5

Pope D, Walker DS, Moss RL (1977) Preparation of cobalt oxide catalysts and their activity for $\mathrm{CO}$ oxidation at low concentration. J Catal 47:33-47

Rauf MA, Ashraf SS (2009) Fundamental principles and application of heterogeneous photocatalytic degradation of dyes in solution. Chem Eng J 151:10-18

Rossin JA (1989) Complete catalytic oxidation of diethyl sulfide over a $1 \% \mathrm{Pt} / \mathrm{Al}_{2} \mathrm{O}_{3}$ catalyst. Ind Eng Chem Res 28:1562-1564

Sclafani A, Herrmann JM (1998) Influence of metallic silver and platinum-silver bimetallic deposits on the photocatalytic activity of titania (anatase and rutile) in organic and aqueous media. J Photochem Photobiol A 113:181-188
Shie JL, Lee CH, Chiou CS, Chang CT, Chang CC, Chang CY (2008) Photodegradation kinetics of formaldehyde using light sources of UVA, UVC and UVLED in the presence of composed silver titanium oxide photocatalyst. J Hazard Mater 155:164-172

Vamathevan A, Amal R, Beydoun D (2002) Photocatalytic oxidation of organics in water using pure and silver-modified titanium dioxide particles. J Photochem Photobiol A 148:233-245

Wang Z, Liu J, Dai Y, Dong W, Zhang S, Chen J (2011) Dimethyl sulfide photocatalytic degradation in a light-emitting-diode continuous reactor: kinetic and mechanistic study. Ind Eng Chem Res 50:7977-7984

Ye SY, Tian QM, Song XL, Luo SC (2009) Photoelectrocatalytic degradation of ethylene by a combination of $\mathrm{TiO}_{2}$ and activated carbon felts. J Photochem Photobiol A 208:27-35

Young C, Lim TM, Chiang K, Scott J, Amal R (2008) Photocatalytic oxidation of toluene and trichloroethylene in the gas-phase by metallised ( $\mathrm{Pt}, \mathrm{Ag}$ ) titanium dioxide. Appl Catal B Environ 78:1-10

Yu H, Zhang K, Rossi C (2007) Theoretical study on photocatalytic oxidation of VOCs using nano- $\mathrm{TiO}_{2}$ photocatalyst. J Photochem Photobiol A 188:65-73

Zuo GM, Cheng ZX, Chen H, Li GW, Miao T (2006) Study on photocatalytic degradation of several volatile organic compounds. J Hazard Mater 128:158-163 